\title{
Successful Treatment of Inflammatory Linear Verrucous Epidermal Nevus with Concomitant Psoriasis Using Etanercept
}

\author{
Reda Hesham Saifaldeen ${ }^{a} \quad$ Mohammad I. Fatani $^{\mathrm{b}} \quad$ Badee Baltow $^{\mathrm{c}}$ \\ Abdulmajeed S. Khan ${ }^{d}$ \\ ${ }^{a}$ Medical Intern, Umm al Qura University, Makkah, Saudi Arabia; ${ }^{b}$ Dermatology Consultant, \\ Hera Hospital, Makkah, Saudi Arabia; ' Consultant Pathologist, Hera General Hospital, \\ Makkah, Saudi Arabia; ${ }^{d}$ Consultant Internist, Hera General Hospital, Makkah, Saudi Arabia
}

\section{Keywords}

Linear psoriasis $\cdot$ Inflammatory linear verrucous epidermal nevus $\cdot$ Etanercept

\begin{abstract}
Linear psoriasis is a rare form of the disease characterized by the linear distribution of lesions involving dermatome or along Blaschko's lines. Clinically, it may resemble inflammatory linear verrucous epidermal nevus; a combination of history, skin examination, and histopathology are required to ensure correct diagnosis and appropriate therapy. This paper describes a case of a 23-year-old male presenting with unilateral erythematous scaly plaques arranged in a linear path on the left leg. Etanercept was initiated after poor response to adalimumab. Improvement of his psoriasis was noted, with PASI 75 reduction after 24 weeks of treatment. Clinical studies have shown excellent efficacy of etanercept, and our patient well tolerated treatment with etanercept for 52 weeks without any adverse effects.
\end{abstract}




\section{Introduction}

Psoriasis is a chronic autoimmune disease characterized by abnormal skin patches, which are typically red, itchy, and scaly. These may differ in severity, from localized to complete body coverage [1]. Psoriasis affects up to $5 \%$ of the world's population [2]. Linear psoriasis is a rare subtype of psoriasis, first described in 1951, with yet unclear pathogenesis, which might be clarified by the well-established concept of genetic mosaicism [3]. Linear psoriasis is often asymptomatic or accompanied by mild pruritus. It can occur in early childhood, in an unusual nevoid distribution along Blaschko's lines [4]. The main differential diagnosis includes inflammatory linear verrucous epidermal nevus (ILVEN).

Regarding treatment, topical therapy is effective in almost all psoriatic patients. However, some patients show exacerbated or severe symptoms and may require systemic treatment, such as methotrexate, cyclosporine, or phototherapy. These conventional treatments have multiple potential adverse effects if used long-term. Therefore, biologic agents have been developed to alter the immunological pathways of psoriasis development $[1,5,6]$. TNF alpha antagonists (adalimumab, etanercept, and infliximab) are considered to be one effective biological treatment for psoriasis.

\section{Case Report}

A 23-year-old male with a 6-year history of psoriasis presented with erythematous scaly plaques on both lower limbs, which followed a linear path, and on both elbows. There was neither history of trauma before the appearance of lesions nor pruritus or other symptoms. The lesions first appeared at the age of 6, involving the left foot only, later developing to involve the left leg. Over the last 7 years, lesions began to appear on the right leg. Family history was negative for a history of psoriasis or other skin diseases.

On examination, scaly erythematous plaques were found exclusively on the left side of the lower limbs, in lines running on the left leg from the anterior aspect to the dorsum of the foot, with silvery, scaly plaque and papule over the right leg, and with multiple psoriatic plaques over both elbows (Fig. 1a, b). The patient was treated with subcutaneous injections of adalimumab for 8 months, with inadequate response.

Our differential diagnosis at that point, besides psoriasis, was ILVEN. A skin biopsy was taken from both legs to better understand the clinical condition, with the histopathologic examination of both showing similar features. Sections showed confluent hyperparakeratosis, loss of granular layer (agranulocytosis), papillomatosis with thin suprapapillary plate, and dilated papillary dermal vessels. Frequent mitoses were identified in the stratum basalis. In the dermis, mild, superficial perivascular lymphohistiocytic infiltrate was appreciated (Fig. 2a-d).

This case exhibited overlapping features of psoriasis and ILVEN, which can be confused clinically and histologically. Papillomatosis is an odd histological feature for psoriasis. Nevertheless, confluent parakeratosis and agranulocytosis, with dilated papillary dermal vessels and Munro's microabscesses, are findings that are most consistent with a diagnosis of linear psoriasis.

A subcutaneous injection of $50 \mathrm{mg}$ etanercept was prescribed twice weekly for 24 weeks, with PASI 75 reduction, followed by a weekly maintenance dosage of $50 \mathrm{mg}$ by subcutaneous injection. The plaques on the legs and elbow had either disappeared completely or thinned and faded (Fig. 3a, b) after 52 weeks of treatment. 


\section{Discussion}

Linear psoriasis is a rare form of psoriasis, with few cases reported in the literature [79]; therefore, there is no estimated prevalence. It can be confused with ILVEN, and the literature has discussed the difference between them $[9,10]$. Regarding these differences, according to Saraswat et al. [11], ILVEN usually develops in the first months of life, progresses slowly, may be intensely pruritic, and is highly refractory to antipsoriatic treatment. Psoriasis, by contrast, usually develops later in life, progresses rapidly, is sometimes pruritic, and responds favorably to antipsoriatic therapy.

Histologically, while ILVEN constantly shows hypergranulosis associated with orthokeratosis that alternates between agranulocytosis and orthokeratosis [12], psoriasis has the classic features of confluent parakeratosis and Munro's microabscesses. In contrast to psoriasis, ILVEN presents with subtle or obvious papillomatosis. The current case showed overlapping features.

Immunohistopathologic studies can help distinguish the two entities. There is a little expression of keratin 10 in psoriasis, while its level remains normal in ILVEN $[9,10]$. Another marker, involucrin, is detectable in psoriasis but absent from ILVEN [13].

The literature reports few cases of linear psoriasis treated by biological agents. Two cases reported by Rott et al. [14] and Sfia et al. [15] were successfully treated by infliximab, one case reported by Colombo et al. [16] was treated by etanercept, and one case reported by Arnold et al. [17] was treated by adalimumab.

We diagnosed our case as overlapping features of linear psoriasis and ILVEN based on history and clinical examination, as well as the histopathological findings. We treated our patient with etanercept $50 \mathrm{mg}$ by subcutaneous injection twice weekly for 24 weeks, with PASI 75 reduction, followed by a maintenance weekly dosage of $50 \mathrm{mg}$ by subcutaneous injection. At follow up visits, complete improvement was shown for both elbows and the right leg, while the left leg and foot showed partial improvement and good response after 52 weeks of treatment.

Ustekinumab (interleukin 12/23) was also used in a linear psoriasis case reported by Weng and Tsai [18] after the patient failed to respond to methotrexate, acitretin, topical vitamin $\mathrm{D}_{3}$ analogs, and steroids. Recently, Ghoneim et al. [19] reported a case of a patient with linear psoriasis started on ixekizumab (interleukin 17), after failing to respond to topical steroids. After 4 months and 8 doses, the patient showed marked improvement, with the skin lesions almost resolved [19].

Several studies have also reported that even though psoriatic lesions may look similar, they vary in the activation of inflammatory and cytokine pathways; such networks may explain the different treatment responses observed to biologic agents [20].

There are no recent, consensus guidelines for the treatment of linear psoriasis, and many future studies are needed to determine the most favorable management of this rare variant.

\section{Conclusion}

We report this case for its rarity of occurrence and its clinical implications for the differential diagnosis of such disease. Furthermore, we mention the therapeutic role played by biological medication, which in our case demonstrated significant resolution. 


\section{Statement of Ethics}

The patient gave written informed consent.

\section{Disclosure Statement}

The authors declare no conflicts of interest.

\section{References}

1 Menter A, Gottlieb A, Feldman SR, Van Voorhees AS, Leonardi CL, Gordon KB, Lebwohl M, Koo JY, Elmets CA, Korman NJ, Beutner KR, Bhushan R: Guidelines of care for the management of psoriasis and psoriatic arthritis: section 1. Overview of psoriasis and guidelines of care for the treatment of psoriasis with biologics. J Am Acad Dermatol 2008;58:826-850.

Naldi L: Epidemiology of psoriasis. Curr Drug Targets Inflamm Allergy 2004;3:121-128.

Happle R: Somatic recombination may explain linear psoriasis. J Med Genet 1991;28:337.

Al-Fouzan A, Hassab-EI-Naby H, Nanda A: Congenital linear psoriasis: a case report. Pediatr Dermatol 1990;7:303-306.

5 Griffiths CE, Iaccarino L, Naldi L, Olivieri I, Pipitone N, Salvarani C, Doria A: Psoriasis and psoriatic arthritis: immunological aspects and therapeutic guidelines. Clin Exp Rheumatol 2006;24:S72-S78.

-6 Smith CH, Anstey AV, Barker JN, Burden AD, Chalmers RJ, Chandler D, Finlay AY, Griffiths CE, Jackson K, McHugh NJ, McKenna KE, Reynolds NJ, Ormerod AD: British Association of Dermatologists guidelines for use of biological interventions in psoriasis. Br J Dermatol 2005;153:486-487.

7 Chien P Jr, Rosenman K, Cheung W, Wang N, Sanchez M: Linear psoriasis. Dermatol Online J 2009;15:4.

8 Purohit S, Kanodia S, Shukla SR, Saxena VN, Meena RS, Saxena V: Linear psoriasis. Indian J Dermatol Venereol Leprol 2006;72:398.

9 Vissers WH, et al: Immunohistochemical differentiation between inflammatory linear epidermal nevus (ILVEN) and psoriasis. Eur J Dermatol 2004;14:216-220.

10 De Jong E, Rulo HF, van de Kerkhof PC: Inflammatory linear verrucous epidermal naevus (ILVEN) versus linear psoriasis. A clinical, histological and immunohistochemical study. Acta Derm Venereol 1991;71:343-346.

11 Saraswat A, Sandhu K, Shukla R, Handa S: Unilateral linear psoriasis with palmoplantar, nail, and scalp involvement. Pediatr Dermatol 2004;21:70.

12 Miteva LG, Dourmishev AL, Schwartz RA: Inflammatory linear verrucous epidermal nevus. Cutis 2001;68:327-330.

13 Ferreira FR, Di Chiacchio NG, DeAlvarenga ML, Mandelbaum SH: Involucrin in the differential diagnosis between linear psoriasis and inflammatory linear verrucous epidermal nevus: a report of one case. An Bras Dermatol 2013;88:604-607.

14 Rott S, Küster RM, Mrowietz U: Successful treatment of severe psoriatic arthritis with infliximab in an 11-year-old child suffering from linear psoriasis along the lines of Blaschko. Br J Dermatol 2007;157:191-192.

15 Sfia M, Roth-Mall B, Tortel MC, Guillaume JC, Cribier B: Blaschko-linear psoriasis revealed by infliximab therapy (in French). Ann Dermatol Venereol 2009;136:898-903.

16 Colombo L, et al: Superimposed linear psoriasis: low effectiveness of biologic therapy. G Ital Dermatol Venereol 2011;146:311-313.

17 Arnold AW, Happle R, Itin PH: Superimposed linear psoriasis unmasked by therapy with adalimumab. Eur J Dermatol 2010;20:573-574.

18 Weng H, Tsai T: Response of superimposed linear psoriasis to ustekinumab: a case report. Indian J Dermatol Venereol Leprol 2017;83:392.

19 Ghoneim S, Ramos-Rodriguez A, Vazquez de Lara F, Bonomo L: The successful treatment of a case of linear psoriasis with ixekizumab. Case Rep Dermatol Med 2017;2017:3280215.

-20 Karczewski J, Poniedziałek B, Rzymski P, Adamski Z: Factors affecting response to biologic treatment in psoriasis. Dermatol Ther 2014;27:323-330. 


\section{Case Reports in Dermatology}
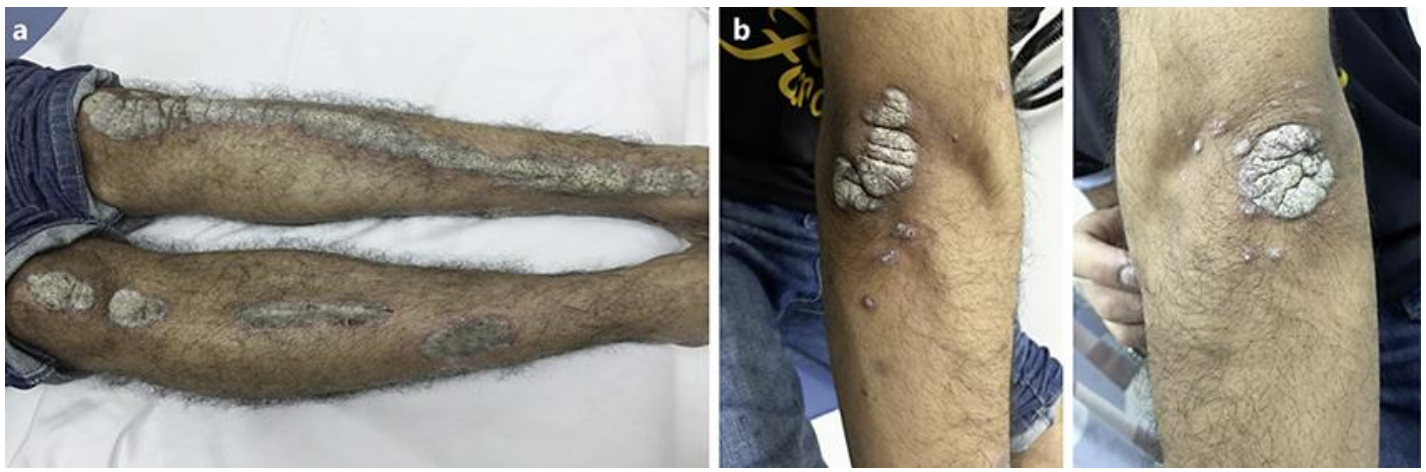

Fig. 1. a Erythematous, scaly plaques involving both legs. b Psoriatic lesions over both elbows.

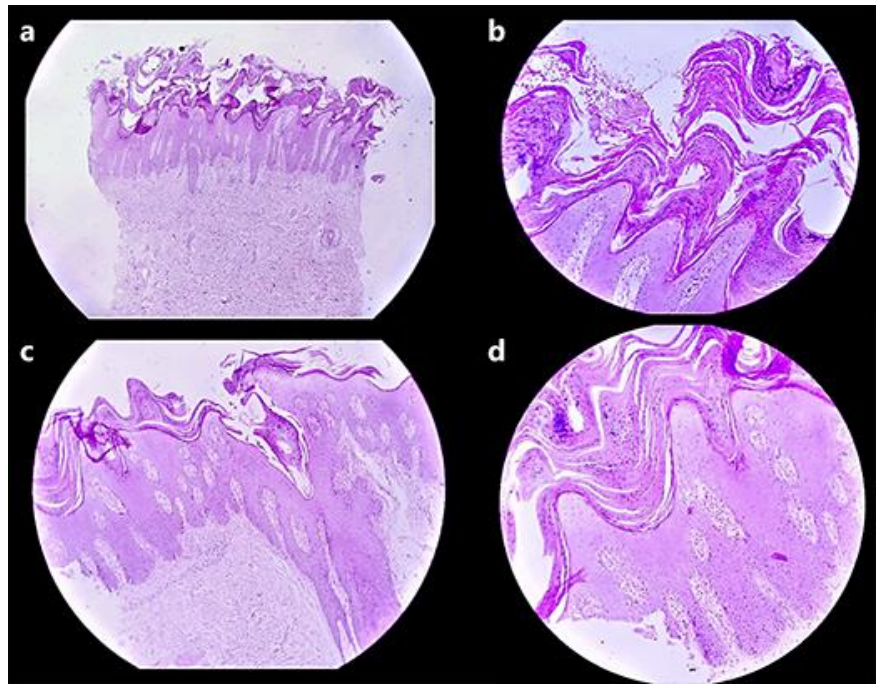

Fig. 2. a Hematoxylin and eosin, $\times 10$. Skin punch biopsy from right leg showing psoriasiform hyperplasia with subtle papillomatosis and hyperparakeratosis. b Hematoxylin and eosin, $\times 40$. Skin punch biopsy from the right leg exhibits almost confluent parakeratosis and an absent granular layer with Munro's microabscesses. Some dilated papillary dermal vessels are noted. c Hematoxylin and eosin, $\times 20$. Skin punch biopsy from left leg showing psoriasiform hyperplasia with subtle papillomatosis and hyperparakeratosis. Absent granular layer is evident, with denuded foci. Also seen is a hair follicle with parakeratotic plugging. d Hematoxylin and eosin, $\times 40$. Skin punch biopsy from left leg exhibiting almost confluent parakeratosis and an absent granular layer with Munro's microabscesses. 


\section{Case Reports in Dermatology}

www.karger.com/cde

Saifaldeen et al.: Successful Treatment of Inflammatory Linear Verrucous Epidermal Nevus with Concomitant Psoriasis Using Etanercept

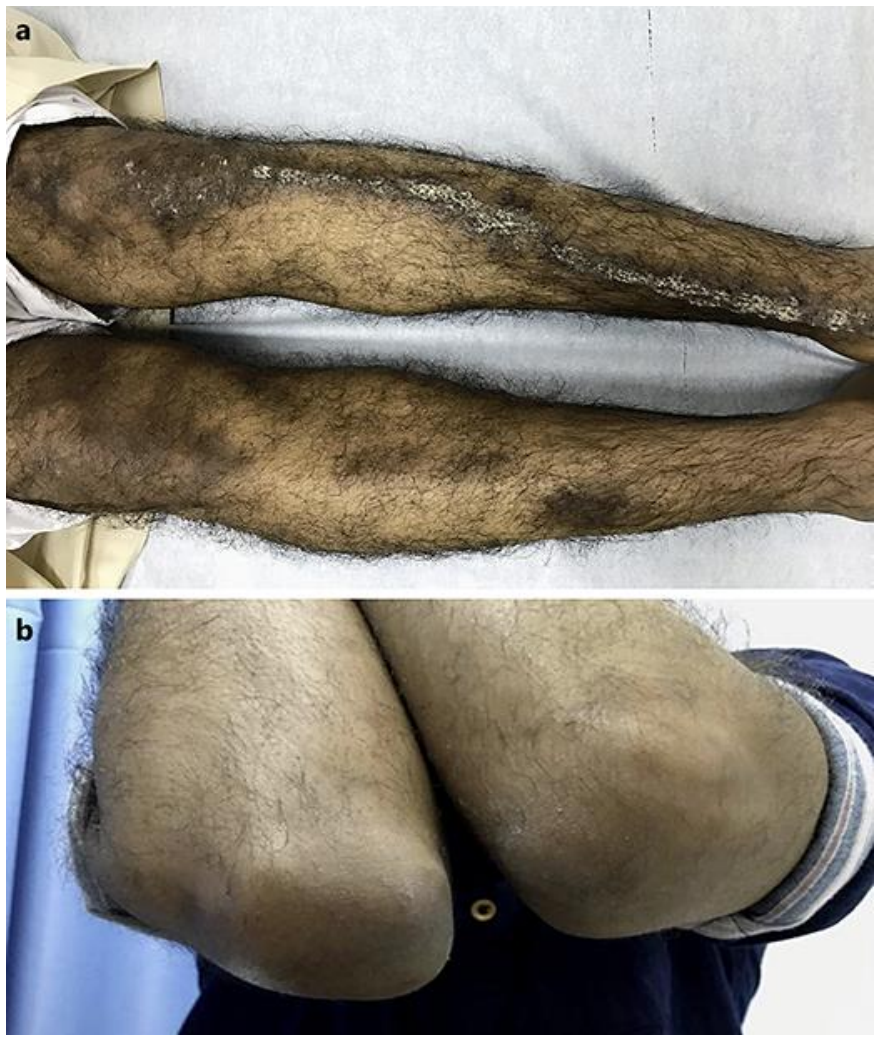

Fig. 3. a Improvement of both legs after 52 weeks of treatment with etanercept. b Improvement of both elbows after 52 weeks of treatment with etanercept. 